(C) [2009] IEEE. Reprinted, with permission, from Zhan, Yuedong; Wang, Hua; Zhu, Jianguo; Guo, Youguang. 2009, 'Fault Monitoring and Control of PEM Fuel Cell as Backup Power for UPS Applications', Proceedings of IEEE Energy Conversion Conference \& Expopp. 631-638. This material is posted here with permission of the IEEE. Such permission of the IEEE does not in any way imply IEEE endorsement of any of the University of Technology, Sydney's products or services. Internal or personal use of this material is permitted. However, permission to reprint/republish this material for advertising or promotional purposes or for creating new collective works for resale or redistribution must be obtained from the IEEE by writing to pubspermissions@ieee.org. By choosing to view this document, you agree to all provisions of the copyright laws protecting it. 


\section{Fault Monitoring and Control of PEM Fuel Cell as Backup Power for UPS Applications}

\author{
Yuedong Zhan, Hua Wang \\ Key Laboratory on Computer Technology Application \\ Kunming University of Science and Technology \\ Kunming, China \\ ydzhan@163.com,wanghua65@163.com
}

\begin{abstract}
This paper presents the expert fault monitoring and intelligent comprehensive control of a proton exchange membrane (PEM) fuel cell (PEMFC) as backup power source for an uninterruptible power supply (UPS) system. The failure status can be shown on the screen of a micro-computer (or a PC) linked with the UPS through an RS-232 and on the control panel of the UPS through LED indicator lights. The proposed intelligent comprehensive monitors and controllers of PEMFC and UPS can supply high quality power with flexible conversion functions, leading to the establishment of reliable power management for UPS applications. Finally, a suitable strategy and technique of fault monitoring and control for a UPS hybrid system with backup PEMFC and battery is implemented. The performances of the monitors and controllers are evaluated by experimental results, showing that the developed UPS system with backup PEMFC and battery power sources is suitable for industry applications.
\end{abstract}

Index Terms-Proton exchange membrane (PEM) fuel cell; uninterruptible power supply (UPS); expert monitoring system; intelligent comprehensive control.

\section{INTRODUCTION}

An uninterruptible power supply (UPS) system is a power conditioning equipment, which can continuously feed loads with high quality power even when a strong perturbation occurs in the utility grid. With the development of information society and the widespread applications of computer process systems, the UPS will be widely used in the field of computers, medical/life support systems, telecommunication, industrial controls, financial securities, aerospace, and office automation. With the development of information technology, power electronic technology and all kinds of advanced control techniques have been widely applied in the design and development of UPS. Therefore, UPS technology will further be in the direction of modularization, intellectualization, digitalization, networking, high frequency, green revolution and so on.

Due to high electrical efficiency, flexibility with respect to power and capacity, long lifetime and no pollutions, the fuel cells are rapidly becoming a significant source of power in our society and the integration of fuel cells with UPS would become a potential market application for extended run-time UPS [1]. Among fuel cell technologies, the proton exchange

\author{
Jianguo Zhu, Youguang Guo \\ School of Electrical, Mechanical and Mechatronic \\ Systems \\ University of Technology Sydney \\ Sydney, Australia \\ joe@eng.uts.edu.au, youguang@eng.uts.edu.au
}

membrane (PEM) fuel cell (PEMFC) and the liquid-fed direct methanol fuel cell (DMFC) are the most promising [2].

In the aspects of failure monitoring and diagnoses for PEMFC, some papers have been published. Hissel et al. [3] explored a fuzzy logic diagnosis method for PEMFC system. Xue et al. [4] proposed a model-based condition monitoring scheme that employs the Hotelling $\mathrm{T}^{2}$ statistical analysis for fault detection of PEMFC. This model-based robust condition monitoring scheme can deal with the operating condition variation, various uncertainties in a fuel cell system, and measurement of noise. Ramschak et al. [5] established a strongly simplified and low cost stack diagnosis unit, in comparison to the cell voltage monitoring (CVM) technology. Ma et al. [6] measured the pressure-drop between the inlet and outlet of the channel, which was used as a diagnostic signal to monitor liquid water accumulation and removal. Riascos et al. [7] realized the failure diagnoses of all kinds of parameters in a PEMFC using Bayesian network method.

To obtain the reliability and the overall performances of PEMFC systems, a number of design and control strategies have been proposed and some examples can be found. Recently, Danzer et al. [8] proposed a model-based control structure consisting of a multivariable control of the cathode pressure and the excess ratio of oxygen using the mass flow controller (MFC) and the outlet throttle as actuators. Yang et $a l$. [9] presented an indirect model reference adaptive control for low-power PEMFC. He et al. [10] designed two controllers: a decentralized classic PI controller and a state feed-back controller. Methecar et al. [11] employed a linear controller to control the power density and temperature of PEMFC. Karnik et al. [12] also used a state space feed-back to control the water balance and pressure, in order to meet the demands of static and dynamic performances. Particularly, Pukrushpan et al. [13] focused on three major control subsystems: fuel and air supply, water management and heat management in the fuel cell systems. Using feedback and feed-forward control, they maintained an excess oxygen ratio and reported the net system power (after subtracting the extra power required for maintaining the excess oxygen ratio and overcoming parasitic losses from the output power) obtained from the fuel cell. 
Regarding the designs and researches of PEMFC-UPS hybrid system, Santi et al. [14] discussed the design process for a fuel-cell-based inverter system, the fuel cell characteristics, and the battery requirements in domestic UPS applications. It examined a large number of possible solutions for system topology. The proposed solution used an active filter and a battery to compensate for the slow dynamics of the fuel cell. Choi et al. [15] proposed a fuel cell-powered UPS system, which consisted of two boost DC/DC converters with fuel cells, and a bi-directional converter with a supercapacitor. Varraraki et al. [16] designed, manufactured and tested a UPS system based on hydrogen technology, which consisted of a 5kW PEMFC running on hydrogen and oxygen, a $210.6 \mathrm{Nm}^{3}$ gas storage section and a water electrolyser for $0.6 \mathrm{Nm}^{3}$ hydrogen and $0.3 \mathrm{Nm}^{3}$ oxygen productions. Change et al. [17] designed a portable PEMFCUPS system powered for computer system. Zhan et al. [18] presented the development of an intelligent uninterruptible power supply (UPS) system with a PEMFC and battery hybrid power sources, focusing on the architecture of UPS hybrid system and the data acquisition and control of PEMFC. The UPS hybrid system architecture consisted of a low cost PEMFC stack, a 3-cell lead-acid battery, an active power factor correction AC/DC rectifier, a half-bridge DC/AC inverter, a DC/DC converter, an AC/DC charger and their control units based on the digital signal processor TMS320F240, other integrated circuit chips, and a simple network management protocol adapter.

Regarding the fault monitoring and control of UPS, the latest research and development show that for a UPS system with hybrid PEMFC and battery/ultracapacitor power sources, with the enlargement of the various society demands and further exploration and development of academic field and industry applications, all kinds of new topological structure, monitoring methods, control strategies, and maintenance management technologies will appear continuously. Li et al. [19] brought the concept of smart UPS and introduced the existing UPS monitoring and control technology. It made a conclusion on a high intelligent control model and estimated the development of the future UPS control technology. In fact, UPS is a matured industry product, when designed, which is considered to have the functions of parameters diagnoses, such as the loop circuit, voltage and temperature of battery, the voltage, current, frequency and phase-order of AC input and output, DC bus voltage, switch circuits states, etc.

In this paper, in order to protect the PEMFC stack from degradation during the operating conditions, a fault monitoring and control system for an industrial UPS system with backup PEMFC and battery power sources is developed. The proposed and designed fault monitoring and control strategies for PEMFC generating system and the power converters of UPS, such as the AC/DC rectifier, the DC/DC converter, and the DC/AC inverter, are evaluated through the experimental tests. Furthermore, to obtain the performance of the PEMFC stack, a comprehensive intelligent controller is presented. Fig. 1 illustrates schematically the structure of a single-phase high-frequency cost-effective UPS system with backup PEMFC and battery hybrid power sources.

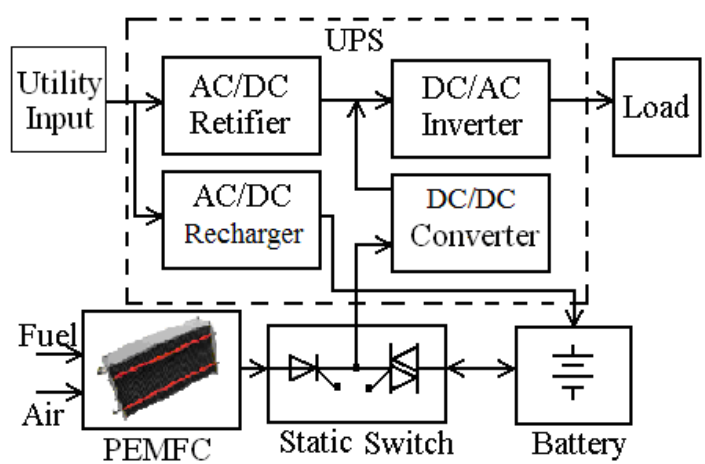

Fig. 1. Scheme of UPS with backup PEMFC and battery power sources

\section{FAULT MONITORING AND CONTROL SYSTEM OF PEMFC GENERATING SYSTEM}

Aiming to avoid the drying and dehydration of PEMFC membrane, realize appropriate water management and balance for obtaining the reliability and the overall PEMFC performance, and preventing the hydrogen and air starvation of electrochemical reaction and leakage of the membrane, an expert monitoring system is designed for conveniently collecting the data and setup parameters of PEMFC, as shown in Fig. 2. Meanwhile, an intelligent comprehensive controller of the PEMFC generating and testing system is also developed, consisting of a power tracking controller, a hydrogen pressure controller, a hydrogen mass flow controller, an air mass flow and thermal controller, and a power switching controller. The data acquisition, the control devices and their software have been developed and can be used to control the whole process of the PEMFC generating and testing system and to measure the operational parameters. In Fig. 2, $\mathrm{SCR}_{1}$ and $\mathrm{SCR}_{2}$ are two silicon-controlled rectifiers, whose control signals are $u_{k_{1}}$ and $u_{k_{2}}$, in order to switch the power sources between the PEMFC and battery for UPS when the load increases sharply, the PEMFC is in failure, or when the input utility grid power source fails.

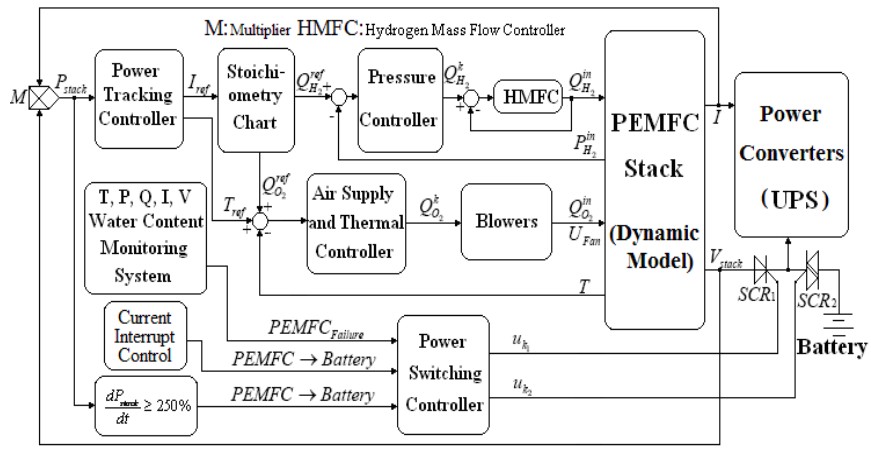

Fig. 2. Configuration of a PEMFC generating system for UPS application 


\section{A. Fault Monitoring system of PEMFC}

There are three fault modes involved in PEMFC failures [4]: the drying and dehydration of the membrane, the hydrogen and air starvation of electrochemical reaction, and the leak of the membrane. Firstly, the electrolyte membrane needs to be appropriately hydrated in order to efficiently conduct the hydrogen protons and prevent the occurrence of localized hot spots. The dehydration and drying of the membrane cause the increase of the internal resistance and a larger output voltage loss, which in turn raises the local temperature of the membrane. If the local overheating lasts for a long period of time, hot spot may occur and eventually permanently damage the membrane. Water transport across the membrane and water content there depend on the combinational effects of the electro-osmotic drag force on the water molecules and water back-diffusion from the cathode side to the anode side. It is believed that the electro-osmosis drag effect is larger than that of the back-diffusion, and the water content of the membrane is mainly dependent on that of the anode side. If the hydrogen is not adequately humidified, the membrane may be dehydrated at the anode side, while dehydration may occur at the cathode side due to water generated by the electrochemical reaction.

Secondly, the hydrogen and air starvation might have several possible causes. The first stage may be caused by the channel flow variation within the stack, that is, the flow resistance directly resulting in the lack of the hydrogen and air in the channels, and consequently the electrolyte hydrogen and air starvation. The reasons include the liquid water droplets forming in the flow channels, the temperature variation, and geometry deviation. In the second stage hydrogen and air starvation may be caused by the electrode pores blocked by the liquid water, which is termed "flooding". This phenomenon generally occurs at the cathode side. The hydrogen and air starvation may interrupt the electrochemical reaction and cause a rapid loss in the output voltage. In the worst situation, it may even lead to the decomposition of the PEMFC component and permanently damage the cells.

Thirdly, the fault mode is the leak of the membrane, which is due to the fracture and/or hole of the membrane. While the holes in the membrane may be caused by the hot spot, the fracture of the membrane is directly resulted from the mechanical stress concentration. Under the dynamic operating conditions, the pressure difference across the MEA may break the membrane.

In this paper, the structure of the proposed expert monitoring system is illustrated in Fig. 3, consisting of a knowledge base (KB), an inference engine (IE), and a user interface system (UIS). The IE is an important component of PEMFC expert monitoring system (PEMFC-EMS). It can infer and solve a design problem by forward-inference, backward-inference or mixed-inference using the information of the knowledge base and measured values of sensors. The UIS is a bridge linking the PEMFC generating system with PEMFC expert monitoring system. According to the measured values of sensors, such as the stack voltage $V_{\text {stack }}$, current $I_{\text {stack }}$, calculated power $P_{\text {stack }}$, and temperature $T_{\text {stack }}$ of the PEMFC stack, and the internal resistance $R_{O h m}$ of stack using current interrupted method, the user interface system transports the information to the inference engine, which infers employing the rules of the knowledge base and gets the results that are sent to the user interface system. The actuators of PEMFC generating system act according to the result information coming from the user interface system.

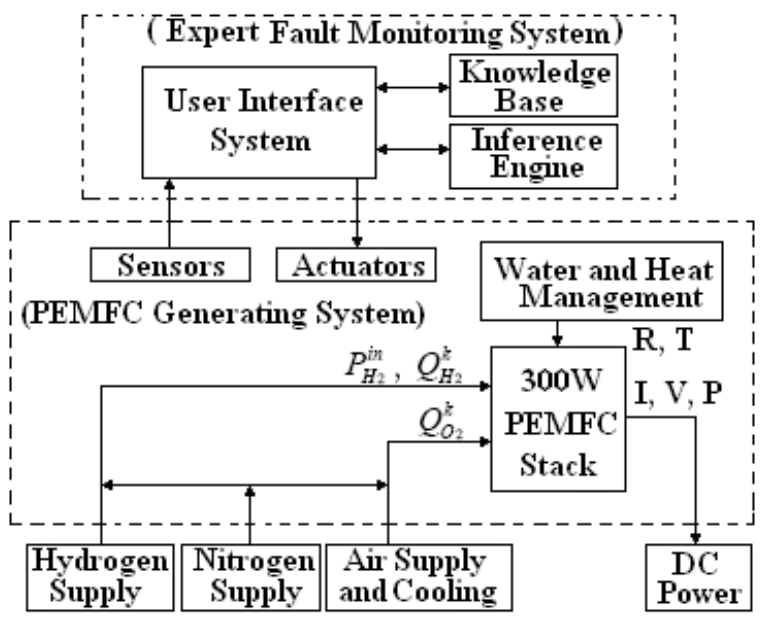

Fig. 3. Structure diagram of PEMFC expert monitoring system

\section{B. Power Tracking Controller}

The objective of the designed power tracking controller is that the mass flow rates can be supplied reasonably for the PEMFC, in order to prevent the hydrogen and air starvation in the PEMFC.

According to the real-time current and voltage of PEMFC stack, the power density (ranging from 12 to $330 \mathrm{~W}$ ) can be firstly calculated. The output power of the fuel cell stack can be calculated by [21].

$$
P_{\text {stack }}=V_{\text {stack }} I_{\text {stack }}
$$

The operating point is at the intersection of the PEMFC power curve and the load power curve, as shown in Fig. 4, which shows the voltage-current and power-current characteristics of the PEMFC stack.

Based on the load at that time, a power tracking controller is designed to continuously distribute the current or real time power by using the setup value of the reference mass flow $Q_{\mathrm{H} 2}^{\text {ref }}$ and $Q^{\text {ref }} \mathrm{O2}$ of hydrogen and air according to the stoichiometry chart of PEMFC. If the load is over $330 \mathrm{~W}$, the controller will shut down the system.

The reference volumetric flow rate of pure hydrogen consumption in standard litres per minute or SL/min is [22] 


$$
Q_{H_{2}}^{r e f}=22.4 \times 60 \times \frac{I N_{c e l l}}{2 F} \times S_{H_{2}}
$$

where $S_{H_{2}}$ is the stoichiometry radio of hydrogen, which is selected within 1.2 1.5.

Because the PEMFC stack selected is an air-breathing and air-cooling fuel cell, that is, air is passing through the cathode compartment in excess of oxygen exact stoichiometry, and the same air is used as a coolant. In the PEMFC generating system, air is supplied by three blowers that are used to cool the stack. The air volumetric mass flow rate in $\mathrm{SL} / \mathrm{min}$ is

$$
Q_{\mathrm{O}_{2}}^{\text {ref }}=22.4 \times 60 \times \frac{M_{\text {Air }} I N_{\text {cell }}}{4 F} \times S_{\mathrm{O}_{2}}
$$

where $M_{\text {Air }}$ is the air mass $(\mathrm{kg})$ and $S_{\mathrm{O}_{2}}$ is the required stoichometric radio, which is selected within 20 30.
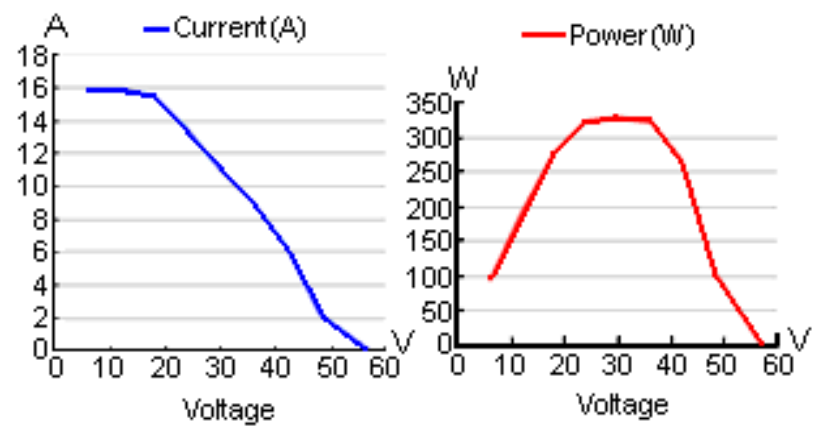

Fig. 4. Voltage-current and power-voltage characteristics of PEMFC

\section{Air Supply and Thermal Controller}

The aim of the designed air supply and thermal controller is that enough air is supplied for PEMFC and the temperature of PEMFC can be controlled in the expected range, in order to avoid the drying and dehydration of the membrane in PEMFC.

The PEMFC belongs to the low temperature stack $(<100$ ${ }^{\circ} \mathrm{C}$ ) in the fuel cell family, but its operating temperature is still higher than the ambient temperature and should be maintained within an appropriate range. The operating temperature is selected according to the characteristics of the PEMFC provided by the manufacturer. In this work, the best operating temperature of the PEMFC is at $50 \sim 60^{\circ} \mathrm{C}$ (the maximum stack temperature is $65^{\circ} \mathrm{C}$ ) according to the operating temperature demands.

Because the thermal model is nonlinear, in order to obtain good control results, in practice, when the stack temperature is less than $50{ }^{\circ} \mathrm{C}$, the thermal controller implements the basic velocity adding digital PI control strategy. On the other hand, because three blowers are used to feed air and cool the stack together, the controller must adjust the three blowers' speed and meet the air mass flows demand of the PEMFC. When the stack temperature is more than $50^{\circ} \mathrm{C}$, a frequency- changing control strategy is employed as the air cooling control.

The air supplying and cooling control rules are:

If $T_{\text {stack }}$ is less than $50^{\circ} \mathrm{C}$, then

$$
Q_{\mathrm{O}_{2}}^{k}=1500+K_{P}\left(T_{\text {ref }}-T(t)\right)+T \int\left(T_{\text {ref }}-T(t)\right) d t(r p m)
$$

If $T_{\text {stack }}$ is between $50^{\circ} \mathrm{C}$ and $60{ }^{\circ} \mathrm{C}$, then $Q_{O_{2}}^{k}=$ adaptive fuzzy control; If $P_{\text {stack }}$ is over $330 \mathrm{~W}$ or $T_{\text {stack }}$ is over $65^{\circ} \mathrm{C}$, then the PEMFC is shut down.

\section{Hydrogen Fuzzy Mass Flow Controller}

The goal of the designed hydrogen fuzzy mass flow controller is that the expected mass flow rates of hydrogen can be precisely controlled and supplied for the PEMFC.

The fuzzy-PI controller input variables are the mass flow error $e(k)$ and the change of error $c(k)$ of hydrogen or air. The output variables of the controller are the optimal $P$ and $I$ gains of a subsequent PI controller device; one of them gives the proportional part $K$ as a function of $e(k)$ and $c(k)$, and the other gives the increment $\Delta T$, which is then integrated to provide the integral term $T$ of the PI controller. A fast response with a small overshoot for the PEMFC system can be achieved with proper handling of the proportional and integral parts. As described in [19], the fuzzy-PI controller is more advantageous than a standard PI controller.

\section{E. Hydrogen Pressure Controller}

The target of the designed hydrogen pressure controller is that the pressure in PEMFC can be controlled in a desired value, in order to avoid the leak of the membrane.

An increase in PEMFC operating pressure results in higher cell voltage according to the Nernst equation and the increase in exchange current density due to increased concentration of reactant gases in the PEMFC electrodes. According to the demands of the PEMFC, this paper adopts the steady pressure equipment to control the reactant gas pressure. The system can also control the hydrogen pressure at about $34.5 \mathrm{kPa}$.

In the PEMFC system, the relation between the pressure (the controlled variable) and the gas flow (the controlling variable) is one-order inertia tache and purely delayed tache arrayed in series, so the digital proportion integral differential (PID) control is the best method. Furthermore, since the control parameters $K_{P}, T_{I}$ and $T_{D}$ are independent to each other, they can be adjusted conveniently.

The control method of PID is used in the pressure controller, that is, the hydrogen output controlling variable is:

$$
\begin{aligned}
Q_{H_{2}}^{k} & =K_{P} e_{H_{2}}(k T)+\frac{T}{T_{I}} \sum_{j}^{k} e(j T) \\
& +\frac{T_{D}}{T}\left[e_{H_{2}}(k T)-e_{H_{2}}(k T-T)\right]
\end{aligned}
$$

where $T$ is the sample period and 


$$
e_{H_{2}}(k T)=Q_{H_{2}}^{r e f}(k T)-P_{H_{2}}^{i n}(k T)
$$

\section{F. Power Switching Controller}

The objective of the designed power switching controller is that according to the monitoring results, the power sources supplied for UPS can be controlled between the PEMFC and battery, in order to prevent the damage of membrane in PEMFC because of the overload, over-temperature, lack of the hydrogen and air in PEMFC.

The complex electrode phenomenon existing in the PEMFC is caused by the double charge layer. This acts as a capacitance and gives the fuel cell stack a smooth dynamic voltage output. When the load of the fuel cell stack changes, the voltage output has an initial Ohm voltage loss due to the resistance of the fuel cell stack and then it slowly moves to a new value. When the load is suddenly increased, the fuel cell may not be able to provide sufficient hydrogen and air to sustain the operation under the new load condition. This can lead to temporary hydrogen and air starvation, thereby causing irreversible damage of the PEMFC stack. On the other hand, in order to monitor the water balance, the openvoltage and current-voltage performance of PEMFC stack, and diagnose the operating processes taking place in the PEMFC, the measurement of the polarization curve and the current interruption control can be used to determine if there is any problem with the PEMFC. To avoid this, in this paper a power switch controller is designed, which can control the power source of UPS to be switched from PEMFC to battery according to the change rate of the power of the PEMFC stack. Transient issues associated with temporary hydrogen and air starvation can be avoided by supplying the power from the battery and slowing down the current drawn from the PEMFC through a change rate limiter of the output power.

On the other hand, in order to monitor the water balance, the open-voltage and current-voltage performance of PEMFC stack, and diagnose the operating processes taking place in the PEMFC, the measurement of the polarization curve and the current interruption control can be used to determine if there is any problem with the PEMFC. In this method, the current is interrupted for a very short period, which is determined by the current value of the stack, and resultant voltage gain is observed and calculated. The difference between the stack voltage before and after the current interrupt, divided by the current, is the stack resistance $R_{\text {Ohmic }}$. A quick measurement of the stack resistance may provide more information about the PEMFC performance. Both dehydration and drying of a cell would result in a loss of voltage, that is, the stack resistance value will be changed. Therefore, the water balance can be reflected by the stack resistance.

\section{FAUlT MONITORING AND CONTROL OF POWER CONVERTERS FOR UPS}

\section{A. Fault Monitoring System of UPS}

In this paper, the proposed topology of power converters, or the power conditioners, is shown in Fig. 5. According to its functionality, the system can be considered as being composed of three main sections. The first section consists of a DC/DC converter whose principal task is to boost the rated output voltage of 36 VDC of PEMFC and battery to a regulated \pm 380 VDC. The second section is an AC/DC rectifier which rectifies the utility input voltage into \pm 380 VDC. The third section is a DC/AC inverter which generates an output voltage of $50 \mathrm{~Hz}, 220$ VAC RMS.

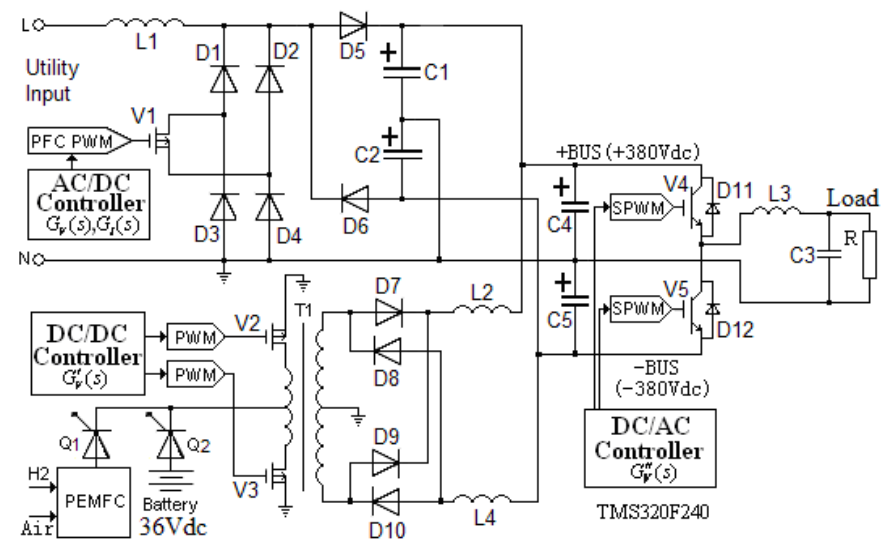

Fig. 5. Power converters for a hybrid UPS system

The developed intelligent UPS hybrid system has the following monitoring functions: [18]

- Monitoring the voltage and current of the PEMFC stack, and deciding if the UPS is supplied by the PEMFC;

- Monitoring the voltage, current and invalidation of the battery, and deciding if the UPS is supplied by the battery, and if the battery is recharged by the AC/DC charger or the PEMFC;

- Monitoring the running status and parameters of the UPS, including the voltages, frequencies, and load percentage of the utility grid input and DC/AC inverter output, the positive and negative bus output voltages of the AC/DC rectifier and DC/DC converter, the UPS temperature, and so on;

- Monitoring the DC auxiliary power sources in the internal UPS;

- Monitoring the overload or short-circuit of UPS output;

- Automatically recording and restoring the faults and alarming information;

- Regularly and automatically testing the UPS itself and the real capacity of battery;

- Automatically calling the operator on duty;

- Displaying the parameters, and controlling and 
recording the failure information when the utility grid power is interrupted or the UPS is improperly working; and

\section{B. Control Strategy of Power Converters}

In the developed UPS hybrid system, the intelligent controller is designed based on TMS320F240 DSP, in which the controlling programs are written into its EPROM. The controller sends signals to the external circuits of the DSP to generate the modulated pulses of the SPWM, as well as measures and records the status of the UPS hybrid system. When faults happen, such as overheated components, overload and over-voltage of UPS, under-voltage of PEMFC stack and battery, the intelligent controller outputs a control signal to blockade the DC/AC inverter, and the UPS hybrid system is switched to the state of BYPASS. The intelligent controller also generates an alarm signal. When the above failures disappear, the UPS hybrid system can be automatically switched to the state of INVERTER.

The intelligent controller can determine the charging mode of the battery. When the utility grid power source is in the normal state, the AC/DC charger works if the battery voltage is lower than the rated value. If the utility grid power source is interrupted, the controller makes the PEMFC charge the battery when necessary.

The block diagrams of the power converters with the control strategies incorporated are shown in Figs. 6 and 7. There are three separate control loops for the AC/DC rectifier control, the DC/DC converter control, and the DC/AC inverter control.

In Figs. 6 and 7, $\mathrm{G}_{\mathrm{I}}(\mathrm{s})$ is the current controller of AC/DC rectifier, $\mathrm{G}_{\mathrm{V}}(\mathrm{s})$ is the voltage controller of $\mathrm{AC} / \mathrm{DC}$ rectifier, $G_{V}^{\prime}(s)$ is the voltage controller of DC/DC converter, and $G_{V}^{\prime \prime}(s)$ is the voltage controller of DC/AC inverter controller.

According to the design method of control theory, the transfer functions of designed controllers for the UPS are given by

$$
\begin{aligned}
G_{V}(s) & =\frac{K_{V}}{1+T_{V} s}=\frac{2.238}{1+0.0022 s} \\
G_{I}(s) & =K_{I}\left(1+\frac{1}{T_{I} s}\right)=2.0 \times\left(1+\frac{1}{0.0003 s}\right) \\
G_{V}^{\prime}(s) & =\frac{K_{V}^{\prime}}{1+T_{V}^{\prime} s}=\frac{1.5}{1+0.0015 s} \\
G_{V}^{\prime \prime}(s) & =\frac{K_{V}^{\prime \prime}\left(1+\tau_{1} s\right)\left(1+\tau_{2} s\right)}{s\left(1+\tau_{3} s\right)\left(1+\tau_{4} s\right)} \\
& =\frac{100(1+0.00169 s)(1+0.000108 s)}{s\left(1+7.9 \times 10^{-6} s\right)\left(1+4.7 \times 10^{-6} s\right)}
\end{aligned}
$$

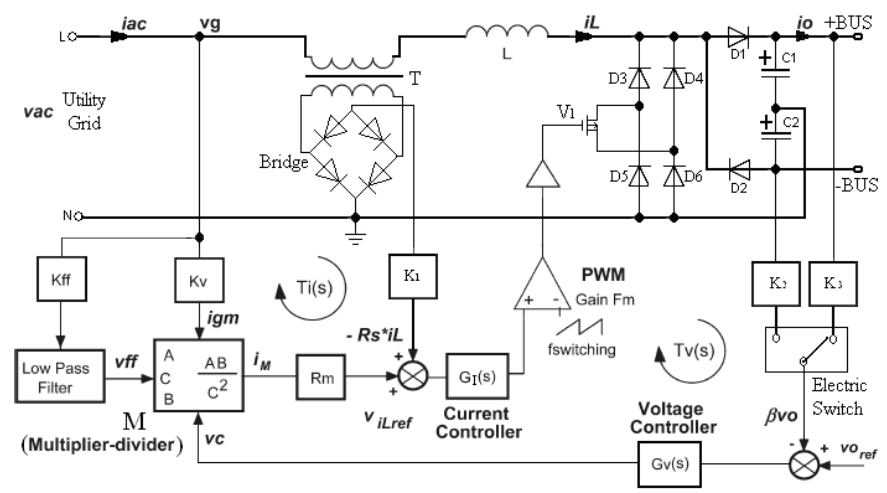

Fig. 6. Schematic diagram of boost AC/DC rectifier

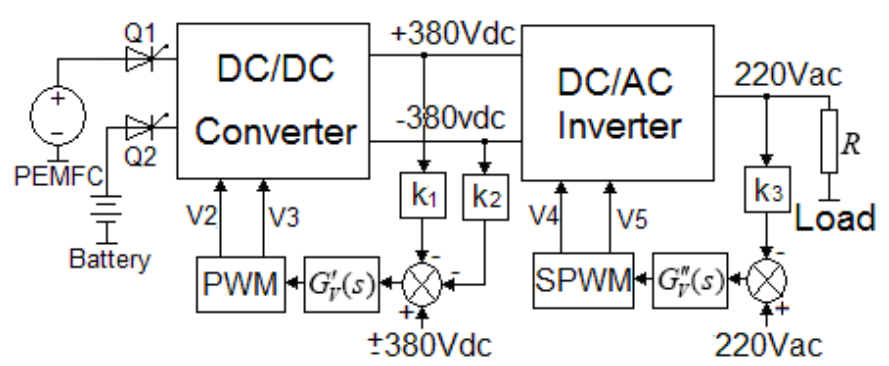

Fig. 7. Schematic diagram of DC/DC and DC/AC power converters

\section{EXPERIMENTAL SETUP AND RESULTS}

The performances of the proposed control strategies of PEMFC generating system and hybrid UPS power converters are tested by building an experimental setup with the following specifications: Input voltage of the utility grid of $160 \mathrm{~V} \sim 275 \mathrm{~V}$ AC, output voltage frequency of $50 \mathrm{~Hz} \pm 5 \%$, PEMFC/battery rated voltage of 36 VDC, and output power of $286 \mathrm{~W}$. The experimental load is a DELL ${ }^{\mathrm{TM}}$ computer, whose model is HP-U2106F3, and the maximum input power is $213 \mathrm{~W}$, and a monitor, whose model is E772p with a power of $73 \mathrm{~W}$. Moreover, a lamp box is used as the supplementary load. Agilent Technologies DSO6034A Oscilloscope, TEKTRONIX AM503 current probe amplifier and P5120 high voltage differential probe are employed as measurement equipments.

The key devices in the system are the hydrogen mass flow controller F-201C-GAS-22V (Bronkhorst ${ }^{\mathrm{TM}}$ ), the temperature and humidity transducer HD2008TV1 (Delta OHM ${ }^{\mathrm{TM}}$ ), the pressure transducer AUS EX 1354X (Barkert ${ }^{\mathrm{TM}}$ ), and so on.

The fault monitoring system of UPS is connected to the network by RS-232 interface connection as shown in the screen interface in Fig. 8. The system can monitor the voltage, capacities and current of the PEMFC and batteries, the current, frequency and voltage of the utility grid input and the inverter output of the UPS, the overload or shirt-circuit of UPS output, and the internal temperature of UPS, etc. Furthermore, the faults and alarming information can be automatically recorded and restored. 


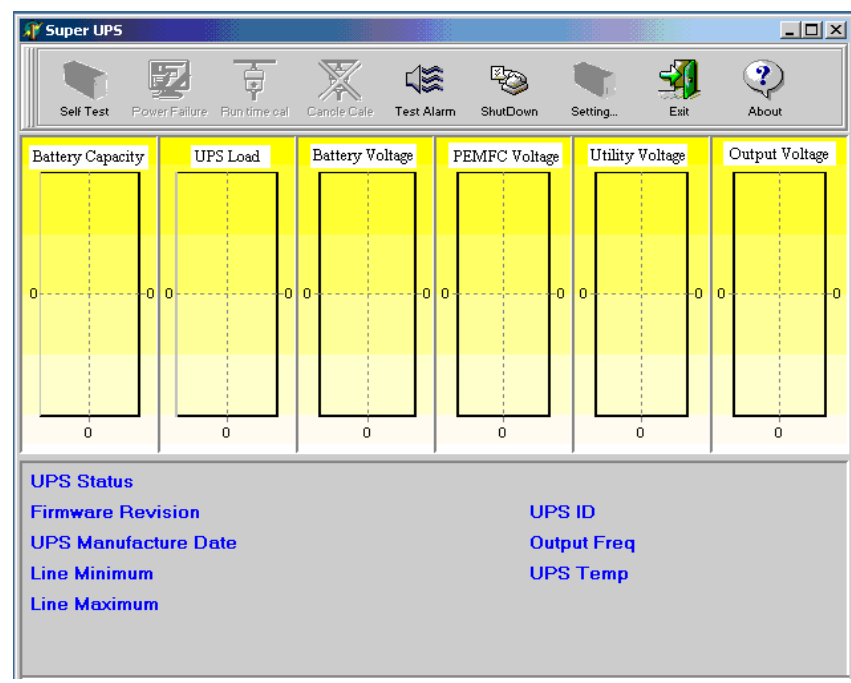

Fig. 8. Monitoring interface of network intelligent UPS

The proposed intelligent comprehensive control strategy is tested and implemented in the PEMFC-UPS hybrid power system. Based on the control software LabVIEW ${ }^{\mathrm{TM}}$, the monitoring and control interface of PEMFC generating system is designed and shown in Fig. 9. In the figure, the valve operating display, the alarm display, the current and voltage of PEMFC and batteries, etc., are shown.

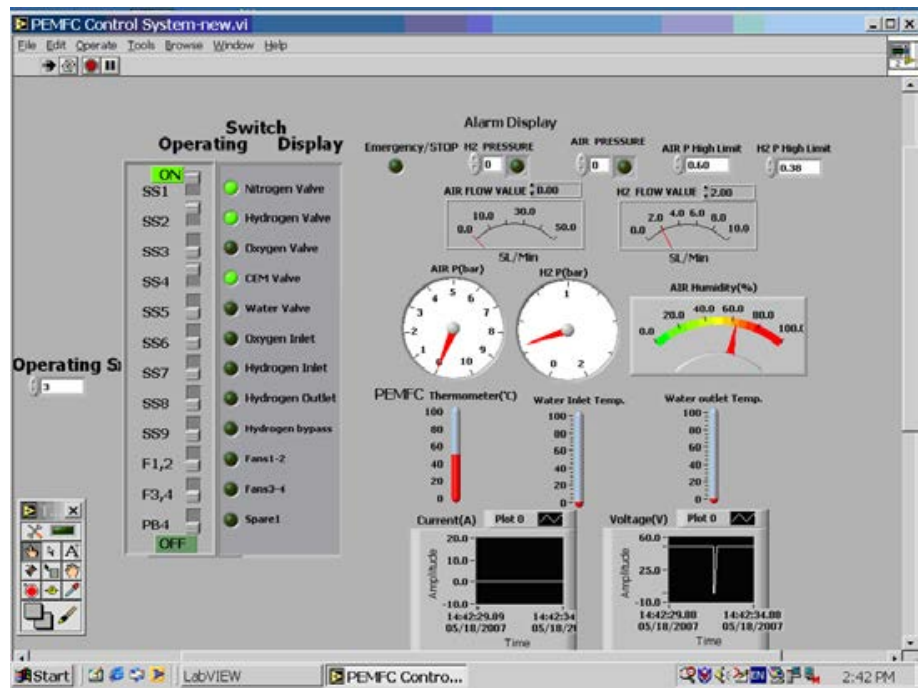

Fig. 9. Monitoring and control interface of PEMFC generating system

Fig. 10 indicates the monitoring parameters and fault types of PEMFC generating system, such as the pressures and mass flow rates of hydrogen and air, the PEMFC temperature, the inlet temperature and outlet temperature of water cooling, the mass flow rates of hydrogen and air, and so on.

Fig. 11 shows the output current and voltage of PEMFC when the load of UPS changes, which proves that the proposed intelligent comprehensive monitoring and control strategy is of the better features, such as fast dynamic response, short rise time, and small overshoot.

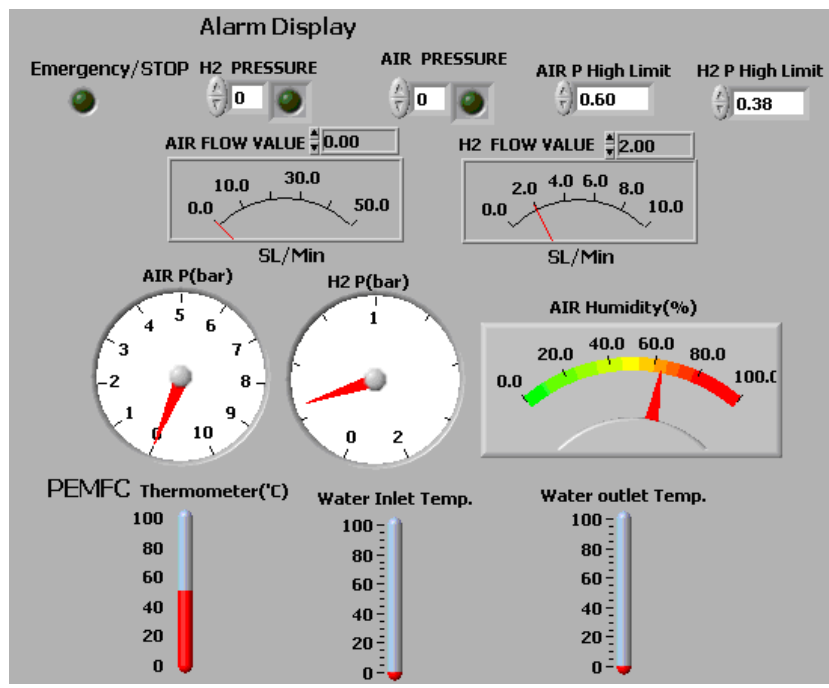

Fig. 10. Monitoring parameters of PEMFC generating system

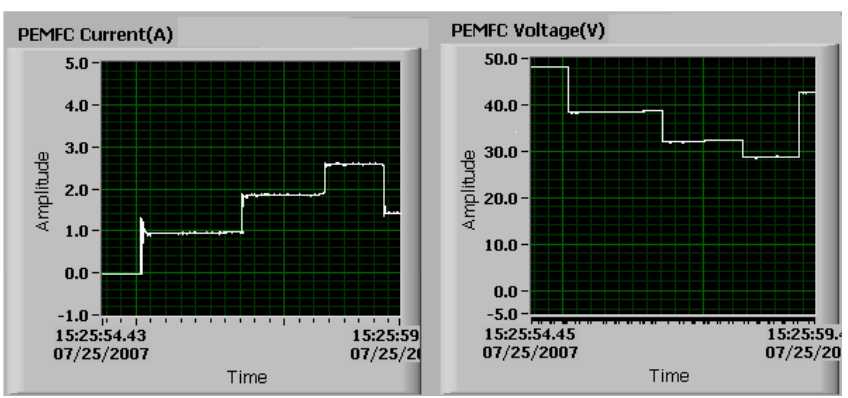

Fig. 11. Output current and voltage of PEMFC generating system when the load changes

With the increase of the load, the temperature of PEMFC stack will go up. Using the thermal controller and the fuzzy adaptive control strategy, the temperature of the stack can be kept in the range of $60 \sim 65{ }^{\circ} \mathrm{C}$, as shown in Fig. 12.

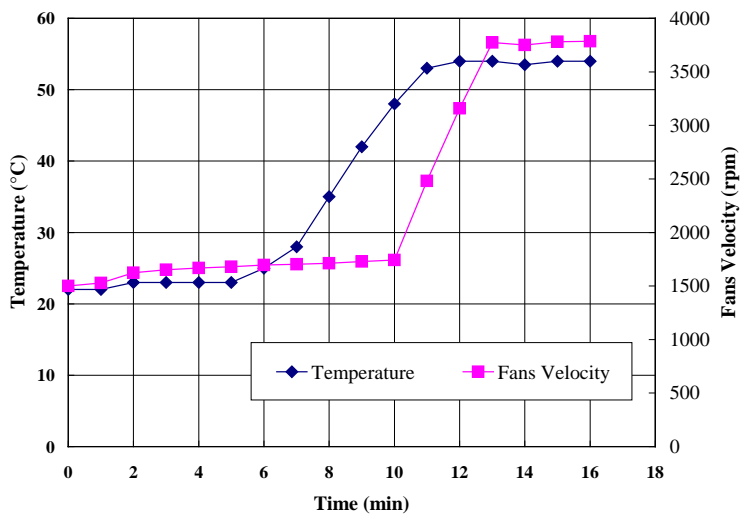

Fig. 12. Stack temperature and fan velocity charts when UPS runs with changing load

The power switching controller can control power sources to switch from PEMFC to battery when the load increases sharply, the current is interrupted, the hydrogen is purged, PEMFC is in failure, or the utility grid power fails. Fig. 13 
shows the current and voltage waveforms of PEMFC when the current is interrupted and the hydrogen is purged.

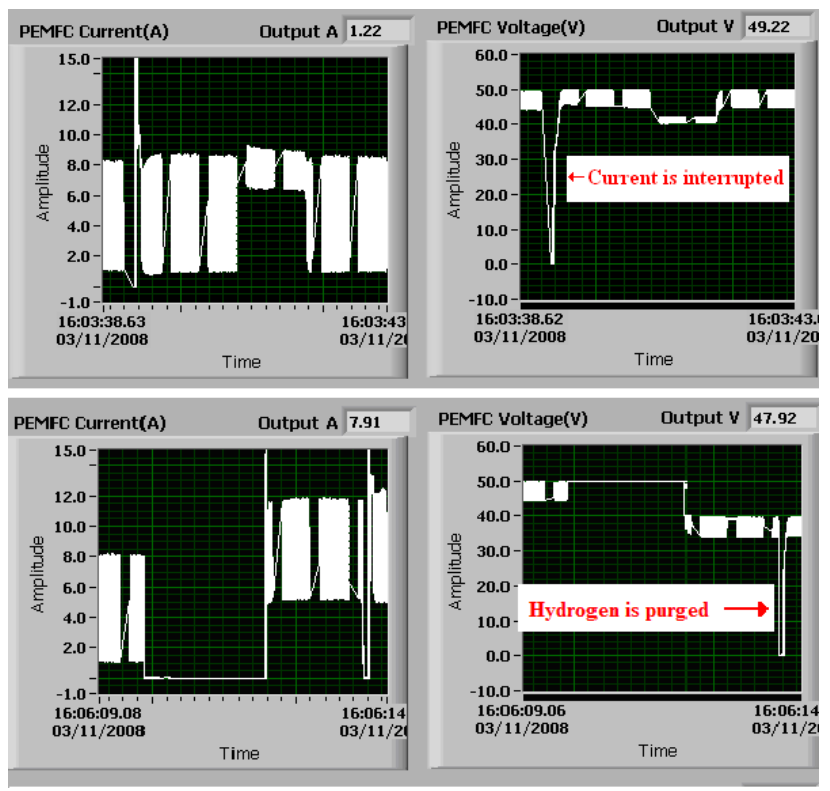

Fig. 13. Current and voltage waveforms of PEMFC when the current is interrupted and the hydrogen is purged

\section{CONCLUSION}

This paper investigates the fault monitoring and control strategy for obtaining the PEMFC performance at different operational conditions and preventing the drying and dehydration of the membrane, the hydrogen and air starvation of electrochemical reaction, and the leak of the membrane. The PEMFC fault monitor system is an expert system, which consists of a knowledge base (KB), an inference engine (IE), and a user interface system (UIS). The intelligent comprehensive controller of PEMFC generating system has been designed to control the power and temperature of stack, the input mass flows and pressures of hydrogen, air mass flows, and the switching of the power sources between the PEMFC and battery. The proposed intelligent comprehensive controller includes the power tracking controller, hydrogen pressure controller, hydrogen mass flow controller, air supply and thermal controller, and power switching controller. The designed monitor and control system of power converters for UPS can on-line monitor and control the operating status and parameters of UPS. The experimental results have proved that the proposed control and monitor scheme can work well.

\section{REFERENCES}

[1] J. Gonzales and G. Tamizhmani. "High efficiency fuel cell based uninterruptible power supply for digital equipment," Journal of Power Sources, vol. 153, pp. 151-156, 2006.

[2] E. Varkaraki, N. Lymberopoulos, E. Zoulias, D. Guichardot, and G. Poli, "Hydrogen-based uninterruptible power supply," Int. J. of Hydrogen Energy, vol. 32, pp. 1589-1596, 2007.
[3] D. Hissel, M. C. Péra, and J. M. Kauffmann, "Diagnosis of automotive fuel cell power generators," Journal of Power Sources, vol. 128, pp. 239-246, 2004.

[4] X. Xue, J. Tang, N. Sammes, and Y. Ding, "Model-based condition monitoring of PEM fuel cell using Hotelling $\mathrm{T}^{2}$ control limit," Journal of Power Sources, vol. 162, pp. 388-399, 2006.

[5] E. Ramschak, V. Peinecke, P. Prenninger, T. Schaffer, and V. Hacker, "Detection of fuel cell critical status by stack voltage analysis," Journal of Power Sources, vol. 157, pp. 837-840, 2006.

[6] H. P. Ma, H. M. Zhang, J. Hua, Y. H. Cai, and B. L. Yi, “Diagnostic tool to detect liquid water removal in the cathode channels of proton exchange membrane fuel cells,” Journal of Power Sources, vol. 162, pp. 469-473, 2006.

[7] L. Riascos, M. Simoes, and P. Miyagi, "On-line fault diagnostic system for proton exchange membrane fuel cells," Journal of Power Sources, vol. 175, pp. 419-429, 2008.

[8] M. A. Danzer, J. Wilhelm, H. Aschemann, and E. P. Hofer, "Modelbased control of cathode pressure and oxygen excess ratio of a PEM fuel cell system,” Journal of Power Sources, vol. 176, pp. 515-522, 2008.

[9] Y. P. Yang, Z. W. Liu, and F. C. Wang, "An application of indirect model reference adaptive control to a low-power proton exchange membrane fuel cell,” Journal of Power Sources, vol. 179, pp. 618-630, 2008.

[10] J. L. He, S. Y. Choe, and C. Hong, "Analysis and control of a hybrid fuel delivery system for a polymer electrolyte membrane fuel cell," Journal of Power Sources, vol. 185, pp. 973-984, 2008.

[11] R. N. Methekar, V. Prasad, and R. D. Gudi, "Dynamic analysis and linear control strategies for proton exchange membrane fuel cell using a distributed parameter model," Journal of Power Sources, vol. 165, pp. 152-170, 2007.

[12] A. Y. Karnik, J. H. Buckland, and J. Sun, "Performance of a PEM fuel cell water management system using static output feedback," in Proc. 2007 American Control Conference, New York, USA, paper ThB06.6, 2007.

[13] J. T. Pukrushpan, A. G. Stefannopoulou, and H. Peng, "Control of fuel cell breathing,” IEEE Control Systems Magazine, pp. 30-46, 2004.

[14] E. Santi, D. Franzoni, A. Monti, D. Patterson, F. Ponci, N. Barry, "A fuel cell based domestic uninterruptible power supply," in Proc. 17th Annual IEEE on Applied Power Electronics Conference and Exposition (APEC 2002), 2002, vol. 1, pp. 605-613.

[15] W. J. Choi, J. W. Howze, and P. Enjeti, "Fuel-cell powered uninterruptible power supply systems: design considerations,” Journal of Power Sources, vol. 157, pp. 311-317, 2006.

[16] E. Varkaraki, N. Lymberopoulos, E. Zoulias. "Hydrogen-based uninterruptible power supply," International Journal of Hydrogen Energy, vol. 32, pp. 1589-1596, 2007.

[17] H. P. Chang, C. L. Chou, and Y. S. Chen. "The design and cost analysis of a portable PEMFC UPS system," International Journal of Hydrogen Energy, vol. 32, pp. 316-322, 2007.

[18] Y. D. Zhan, Y. G. Guo, J. G. Zhu and H. Wang, "Intelligent uninterruptible power supply system with backup fuel cell/battery hybrid power source," Journal of Power Sources, vol. 179, pp. 745753, 2008.

[19] X. H. Li, J. D. Wu, and X. N. He, "General on UPS control technology,” Telecom Power Technology (China), vol. 1, pp. 18-20, 2003.

[20] Horizon Technology, 300W Fuel Cell Stack Operating Instruments, www.horizonfuelcell.com.

[21] Y. D. Zhan, J. G. Zhu, Y. G. Guo, H. Wang, “Comprehensive control of proton exchange membrane fuel cell as backup power supply for UPS," in Proc. $27^{\text {th }}$ Chinese Control Conference, Kunming, Yunnan, China, 16-19 July 2008, pp. 646-651.

[22] F. Barbir, FEM Fuel Cell: Theory and Practice, Elsevier Academic Press, New York, 2005. 